\title{
The effect of Phaseolus vulgaris pods extract on cytokines profile in the condition of alkali burn esophagus 2 degree
}

\author{
Yana Raetska, Viktor Dmytryk, Nataliia Chornenka ${ }^{*}$, Tetiana Halenova, Nataliia Raksha, Tetiana Vovk, \\ Olexiy Savchuk, Ludmila Ostapchenko
}

Department of Biochemistry,

Educational and Scientific Center" Institute of Biology and Medicine" of Taras Shevchenko National University of Kyiv, Ukraine

\section{Correspondence}

Nataliia Chornenka, Email: nata.chornenka24@gmail.com

\section{History}

- Received: Jul 26, 2019

- Accepted: Sep 02, 2019

- Published: Sep 202019

DOI :

https://doi.org/10.15419/bmrat.v6i9.563

\section{Check for updates}

\section{Copyright}

(c) Biomedpress. This is an openaccess article distributed under the terms of the Creative Commons Attribution 4.0 International license.

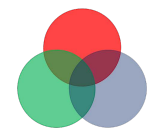

\begin{abstract}
Introduction: As a result of alkaline substances entering the esophagus wall, necrosis occurs, as well as destruction of the mucous, submucosal and muscular layers of the esophagus. The cellular immune system plays an important role in regulating the various phases of the wound healing process, during which, depending on the time and through specific adhesion interactions, polymorphonuclear leukocytes, macrophages, and lymphocytes penetrate the site of the trauma and lead to an intensive proliferation of fibroblasts, endothelial cells, and keratinocytes. The substances of natural origins based on polyphenolic compounds are possible as a remedy for the normalization of physiological and biochemical parameters in a condition of various pathologies. Phaseolus vulgaris pods extract (PVPE) are an example of a rich source of bioactive compounds with proven human health benefits. Our results revealed imbalance of pro-inflammatory and anti-inflammatory cytokines in esophageal homogenates in rats with alkali burn of esophagus II degree, which can indicate a prolonged inflammation in the burned area. In the groups of animals with the alkaline burn of the esophagus, that were injected extract there can be traced a change of the indicators in the direction of normalization, indicating about the therapeutic effect of aqueous extract of pods of Phaseolus vulgaris. Objective: The cellular immune system plays an important role in regulating the various phases of the wound healing process, and can be used as a marker of pathological post-burn wound healing, Phaseolus vulgaris pods extract (PVPE) are an example of a rich source of bioactive compounds with proven human health benefits. The aim of the study was to investigate changes in cytokines levels in rat esophageal supernatants in the condition of alkali burn esophagus second degree (AEB 2) and treatment with Phaseolus vulgaris pods extract. Material and Methods: The animals were experimentally simulated with the alkali esophageal burn with $20 \%$ (grade II) solvent of $\mathrm{NaOH}$. Levels of cytokines in esophageal tissue homogenates were done by ELISA. Results: In the present study, we investigate the imbalance of pro-inflammatory and anti-inflammatory cytokines in esophageal homogenates in rats with AEB 2, which can indicate a prolonged inflammation in the burned area. In the groups of animals with the AEB 2, that were injected extract there can be traced a change of the indicators in the direction of normalization. Conclusion: The administration of the extract, in conditions of alkaline burn of the esophagus, contributes change of the indicators in the direction of normalization indicating the therapeutic effect of aqueous extract of pods of Phaseolus vulgaris.
\end{abstract}

Key words: chemical burns, cytokines, esophageal burn, inflammation, phaseolus vulgaris

\section{INTRODUCTION}

In the modern world, cases of poisoning with chemical agents are increasingly occurring. Chemical burns are the most common pathology of the esophagus in children ${ }^{1}$. Alkaline solutions are often bottled, or placed to wrappers similar to sweets, so children can swallow the alkaline. As a result of alkaline substances entering the esophagus wall, necrosis occurs, as well as destruction of the mucous, submucosal and muscular layers of the esophagus ${ }^{2,3}$. Despite the wide range of drugs used to treat the effects of chemical burns of the esophagus, there is a lack of information in the literature about their effectiveness ${ }^{4}$.
The process of wound healing consists of three phases that overlap with each other: inflammation, proliferation, and remodeling. An alkaline burn of the esophagus induces an inflammatory response that is characterized by the release of pro-inflammatory and anti-inflammatory cytokines ${ }^{5}$. Inflammation is needed to successful burn wound healing. Inflammatory mediators such as cytokines, kinins, lipids, and others provide immune signals to recruit leukocytes and macrophages that initiate the proliferative phase $^{6}$. Inflammation phase is controlled by the balance between pro- and anti-inflammatory mediators in a complex cytokine network. Cytokine balance is 
essential for cell adhesion control, movement, proliferation, and synthesis of extracellular matrix proteins within the healing wound ${ }^{7}$. Prolonged inflammation is harmful and may impend the progress of normal burn wound healing by affecting other stages of wound healing ${ }^{8}$. Prolonged inflammation has also been associated with excessive scarring ${ }^{9}$. According to modern concepts of burn disease development, one of the major burn complications is the occurrence of inflammation $^{10}$.

Wound healing in rodents is very similar to humans, and rodents model are a well-characterized model of human wound healing ${ }^{11}$. There are many difficulties in treating chemical burns of the esophagus ${ }^{1}$. The effect of therapeutic approaches is reduced due to a decrease in the immune balance, and this is due to pathogenic microflora. As a consequence, the complication of regeneration and other abnormalities in patients. The recovery of functional immunity is a very important step in the complex therapy of chemicalinduced esophageal burns.

Analysis of recent data from the literature suggests that substances of natural origins based on polyphenolic compounds are possible as a remedy for the normalization of physiological and biochemical parameters in a condition of various pathologies. Phaseolus vulgaris pods extract (PVPE) are an example of a rich source of bioactive compounds with proven human health benefits ${ }^{12}$. However, this study was designed to explore the anti-inflammatory activity of Phaseolus vulgaris pods extract by measuring their effects on pro-inflammatory and anti-inflammatory cytokines secretion in post-burn esophageal tissue homogenates.

\section{METHODS}

\section{Preparation of plant extract}

Plant material was harvested and collected in Kyiv region of Ukraine. The aqueous extract was prepared by the next method: $132 \mathrm{~g}$ of dried pods of $P$. vulgaris was poured into 1.0 liter of water at $100^{\circ} \mathrm{C}$. The mixture was held in a boiling water bath for 20 minutes, then allowed to cool for overnight and filtered. The obtained extract was centrifuged at $1000 \mathrm{~g}$ for $10 \mathrm{~min}$, for removing plant debris, and the supernatant was dried using The Telstar LyoQuess freeze dryer (Spain). Dry extract $(8 \mathrm{~g})$ was stored at $-20^{\circ} \mathrm{C}$ until the time of use. When needed, the residual extract was suspended in distilled water and used in the study ${ }^{12}$.

\section{Experimental animals}

White non-linear male rats, each in the weight range of 100-120g, were obtained from the Animal house of Taras Shevchenko National University of Kyiv, Ukraine. The animals were kept on a standard vivarium diet. The protocol of the experiments in this study have been examined and approved by the Bioethics Commission of Educational and scientific center "Institute of biology and medicine" of Taras Shevchenko National University of Kyiv, Ukraine (protocol №3 from 15.08.2018) and have been performed in accordance with the standards of the Helsinki declaration (International medical assemble), European Convention for the protection of vertebrate animals that used for experimental and other scientific purposes, and other international agreements and national legislation in this field.

\section{Experimental design}

A total of 160 rats were divided into 4 groups in equal amount (40 rats in each group): group $1^{\text {st }}(\mathrm{G} 1)$ - intact control rats (saline injection), group $2^{\text {nd }}(\mathrm{G} 2)$ - control rats, which was injected with PVPE start from $2^{\text {nd }}$ day of the experiment at a dose of $200 \mathrm{mg} / \mathrm{kg}$ b.w. per day ${ }^{12}$ for 21 days, group $3^{\text {rd }}$ (G3)- AEB 2 with saline injection, group $4^{\text {th }}(\mathrm{G} 4)$-AEB of $2^{\text {nd }}$ grade, which was injected with PVPE start from the $2^{\text {nd }}$ day of the experiment at a dose of $200 \mathrm{mg} / \mathrm{kg}$ b.w. per day for 31 days. Before modeling of esophageal burn, each rat was anesthetized with $50 \mathrm{mg} / \mathrm{kg}$ ketamine $\mathrm{HCl}$ intramuscular. The animals were experimentally simulated with the alkali esophageal burn with $20 \%$ (grade II) solvent of $\mathrm{NaOH}^{1}$. After 7, 14, 21 and 31 days, the animals were killed by cervical dislocation.

\section{Analytical methods}

Histopathological examination for all the groups was done to confirm the tissue damage and stage of alkali burn of esophagus. Levels of cytokines in homogenates were done by ELISA immune assays with primary and secondary antibodies from Santa Cruz Biotechnology, CA, USA. ELISA plates were coated overnight at $4^{\circ} \mathrm{C}$ with samples of esophageal homogenate previously diluted with Tris- $\mathrm{HCl}$ buffer, $\mathrm{pH} 7.4$ to the obtained concentration of proteins 10 $\mu \mathrm{g} / \mathrm{mL}$. After being washed, plates were blocked with $5 \%$ nonfat dry milk for $1 \mathrm{~h}$ at $37^{\circ} \mathrm{C}$ and washed again. After that plates were incubated for $1 \mathrm{~h}$ at $37^{\circ} \mathrm{C}$ with specific primary antibodies against the cytokines. Plates were washed and incubated for $1 \mathrm{~h}$ at $37^{\circ} \mathrm{C}$ with corresponding secondary antibodies conjugated to horseradish peroxidase. After washing, the substrate (OPD and hydrogen peroxide) was added. The reaction was stopped by addition of $2.5 \mathrm{~N} \mathrm{H}_{2} \mathrm{SO}_{4}$. Plates were read at $492 \mathrm{~nm}$ by a microplate reader $\left(\mu\right.$ QuantTM, BioTek Instruments, Inc) ${ }^{13}$. 


\section{Statistical analysis}

The data of biochemical estimations were reported as mean \pm SE for ten animals in each group (after $7^{\text {th }}, 14^{\text {th }}, 21^{\text {st }}$, and $31^{\text {st }}$ days after burn). Statistical analyses were performed using one-way analysis of variance (ANOVA). To determine the reliability of the differences between the two samples we used the Student test $(\mathrm{t})$. Whereby differences $\mathrm{P}<0.05$ were deemed reliable. All statistical analyses were performed with statistically available software (SPSS 16 for WINDOWS).

\section{RESULTS}

We investigated the changes in levels of proinflammatory cytokines (IL- $1 \beta$, IL-6, IL-12 $\beta$, IFN- $\gamma$, TNF- $\alpha$ ). The levels of pro-inflammatory cytokines in esophageal supernatants of rats with AEB 2 was significantly increased (except TNF- $\alpha$ ) over time in groups G3 and G4. Peak levels of pro-inflammatory cytokines were detected on the $7^{\text {th }}$ day and some cytokines levels were constantly and significantly higher up to the $31^{s t}$ day.

The level of IL- $1 \beta$ in group G3 increased by $64.3 \%$, $43.5 \%, 38.6 \%$, and $6.8 \%$ after $7^{\text {th }}, 14^{\text {th }}, 21^{\text {st }}$ and $31^{\text {st }}$ days post-burn (Table 1), when compared to the control (G1). In the group of animals treated with the extract (G4), the level of IL- $1 \beta$ was decreased over experiment time (Table 1), mostly for the 7th-day post burn by $23.6 \%$ compared to the values in group G3 (with no treatment). The level of IL-6 (Table 2) in group G3 increased on 7, 14, 21 and 31 days by $51.2 \%, 26.8 \%, 16.3 \%$, and $6.5 \%$ compared to $\mathrm{G} 1$. As for G4, the level of IL-6 was decreased over experiment time, mostly for the 7 th day by $12 \%$ compared to G3. The level of IL-12 $\beta$ (Table 3) in group G3 increased after 7, 14, 21 and 31 days - by $47.1 \%$, $41.9 \%, 8.9 \%$, and $4.7 \%$ compared to $\mathrm{G} 1$. As for G4, the level of IL-12 $\beta$ was decreased over experiment time, mostly for 14 th day by $11.9 \%$ compared to the values in group G3. The level of TNF- $\alpha$ (Table 4) in group G3 increased on day $7^{\text {th }}$ - by $32.2 \%$ and then, significantly decreased by $19.3 \%, 14.8 \%$ and $8.8 \%$ after 14,21 and 31 days compared to the control (G1). The level of IFN- $\gamma$ (Table 5) in group G3 significantly increased on days 7 and 14 - by $22.1 \%$ and $17.1 \%$ compared to G1.

We investigated the changes in levels of antiinflammatory cytokines (IL-4, IL-10). The results indicated a significant decrease in the levels of antiinflammatory cytokines within 21 days after burning. The level of IL-4 (Table 6) in group G3 decreased after 7 and 14 days - by $22.3 \%$ and $17 \%$ compared to G1. As for G4, the level of IL- 4 was higher by $8.5 \%$ and $5.8 \%$ after 7 and 14 days compared to the values in group G3 (Table 2). Also, the level of IL-10 (Table 7) was significantly lower by $31.3 \%$ for the $7^{\text {th }}$ day and by $39.5 \%$ for the $14^{\text {th }}$ day compared to control. In the group with PVE treatment (G4), the level of IL-10 was significantly higher by $7.3 \%$ for the $7^{\text {th }}$ day and by $22 \%$ for the $14^{\text {th }}$ day compared to the group with no treatment (G3).

\section{DISCUSSION}

In the condition of esophageal chemical burns, the organism is capable of expression of non-specific inflammatory reactions, leading to cytokine synthesis in the burned area ${ }^{10}$. The cellular immune system plays an important role in regulating the various phases of the wound healing process, during which, depending on the time and through specific adhesion interactions, polymorphonuclear leukocytes, macrophages, and lymphocytes penetrate the site of the trauma and lead to an intensive proliferation of fibroblasts, endothelial cells, and keratinocytes ${ }^{14}$. Proinflammatory cytokines play a key role in the progression of inflammatory trauma both at the local and systemic levels. In strong inflammatory conditions, cytokines can enter the bloodstream, eliciting acute responses from various tissue organs.

The imbalance in the release of pro-inflammatory and anti-inflammatory cytokines may contribute to immunological dysfunction and systemic inflammation, resulting in tissue damage, multiple organ failure, or death from the burn ${ }^{15}$. The burn wound healing process characterized by a prolonged inflammatory phase, and that is one of the main complications caused by chemical burns. Due to violations of the skin barrier, sepsis occurs and the immune system weakens ${ }^{10}$.

Acute inflammatory response is initiated due to the activation of tissue macrophages and the secretion of inflammatory cytokines, in particular, interleukin (IL-1), tumor necrosis factor (TNF- $\alpha$ ), IL-6, which cause many local and systemic changes detected during the development of an acute inflammatory response $^{16}$. IL-1 launches a complex of local defense reactions involving almost all types of inflammatory effector cells in the elimination of the pathogen and the restoration of the integrity of the damaged tissue ${ }^{17}$. This local cytokine production has multiple local and systemic consequences, such as inflammatory cell migration, activation of immune response and changes in the processes of proliferation and differentiation of keratinocytes and of fibroblasts ${ }^{10,17}$. 
Table 1: IL-1 $\beta$ levels (st.u.) in esophageal tissue homogenates obtained from the rats

\begin{tabular}{ccccc}
\hline IL-1 $\beta$ (st.u.) & 7 days & 14 days & 21 days & 31 days \\
\hline G1 & $29.75 \pm 1.3$ & $29.3 \pm 1.3$ & $33.2 \pm 2.4$ & $29.92 \pm 2.3$ \\
G2 & $31.6 \pm 1.4$ & $30.15 \pm 2.3$ & $32.94 \pm 2.3$ & $31.54 \pm 2.5$ \\
G3 & $48.89 \pm 3.2^{\star}$ & $42.05 \pm 3.9^{*}$ & $46 \pm 2.2^{\star}$ & $31.97 \pm 2.4$ \\
G4 & $41.88 \pm 3.1^{* \#}$ & $37.72 \pm 3.8^{*}$ & $40.26 \pm 2.1^{\star \#}$ & $31.82 \pm 2.7$ \\
\hline
\end{tabular}

Values are represented as mean $\pm \mathrm{SE}\left({ }^{*} \mathrm{P} \leq 0.05\right.$ compared to control group $\mathrm{G} 1, \# \mathrm{P} \leq$ 0.05 compared to the G3). G1: control rats, G2: control rats injected with PVPE, G3: alkali esophageal burn; G4: alkali esophageal burn with PVPE treatment. Data obtained from groups of ten rats each $(\mathrm{n}=10)$.

Table 2: IL-6 levels (st.u.) in esophageal tissue homogenates obtained from the rats

\begin{tabular}{ccccc}
\hline IL-6 (st.u.) & 7 days & 14 days & 21 days & 31 days \\
\hline G1 & $28.42 \pm 1.2$ & $28.36 \pm 2.1$ & $28.95 \pm 2.1$ & $29.35 \pm 2.1$ \\
G2 & $30.25 \pm 1.5$ & $29.34 \pm 2.2$ & $29.79 \pm 2.4$ & $30.78 \pm 2.6$ \\
G3 & $42.97 \pm 4.1^{*}$ & $35.96 \pm 2.9^{*}$ & $33.7 \pm 2.3^{*}$ & $31.26 \pm 2.8$ \\
G4 & $39.54 \pm 3.6^{*}$ & $32.94 \pm 3.2$ & $31.97 \pm 2.2$ & $30.72 \pm 2.3$ \\
\hline
\end{tabular}

Values are represented as mean $\pm \mathrm{SE}\left({ }^{\star} \mathrm{P} \leq 0.05\right.$ compared to control group $\mathrm{G} 1,{ }^{\#} \mathrm{P}$ $\leq 0.05$ compared to the G3). G1: control rats, G2: control rats injected with PVPE, G3: alkali esophageal burn; G4: alkali esophageal burn with PVPE treatment. Data obtained from groups of ten rats each $(n=10)$.

Table 3: IL-12 $\beta$ levels (st.u.) inesophageal tissue homogenates obtained from the rats

\begin{tabular}{ccccc}
\hline IL-12 $\beta$ (st.u.) & 7 days & 14 days & 21 days & 31 days \\
\hline G1 & $27.67 \pm 1.2$ & $27.31 \pm 2.0$ & $26.78 \pm 1.4$ & $27.67 \pm 1.9$ \\
G2 & $27.97 \pm 1.1$ & $28.64 \pm 2.1$ & $25.34 \pm 1.1$ & $27.99 \pm 2.1$ \\
G3 & $40.71 \pm 4.0$ & $38.7 \pm 3.5^{*}$ & $29.16 \pm 2.7$ & $28.96 \pm 2.2$ \\
G4 & $38.31 \pm 3.8$ & $35.51 \pm 2.4^{*}$ & $29.07 \pm 2.1$ & $28.74 \pm 2.1$ \\
\hline
\end{tabular}

Values are represented as mean $\pm \mathrm{SE}\left({ }^{\star} \mathrm{P}<0.05\right.$ compared to control group $\mathrm{G} 1$, \#P $\leq 0.05$ compared to the G3). G1: control rats,G2: control rats injected with PVPE, G3: alkali esophageal burn; G4: alkaliesophageal burn with PVPE treatment. Data obtained from groups of ten rats each $(n=10)$.

Table 4: TNF- $\alpha$ levels (st.u.) in esophageal tissue homogenates obtained from the rats

\begin{tabular}{ccccc}
\hline TNF- $\alpha$ (st.u.) & 7 days & 14 days & 21 days & 31 days \\
\hline G1 & $26.7 \pm 1$ & $26.71 \pm 1.8$ & $26.88 \pm 1.0$ & $26.41 \pm 1.4$ \\
G2 & $27.24 \pm 1$ & $27.53 \pm 1.6$ & $26.95 \pm 1.1$ & $26.89 \pm 2.7$ \\
G3 & $35.31 \pm 4.4^{*}$ & $21.54 \pm 1.4^{*}$ & $22.9 \pm 1.9^{*}$ & $24.07 \pm 2.4$ \\
G4 & $34.53 \pm 3.8^{*}$ & $21.99 \pm 1.6^{*}$ & $22.59 \pm 2.1^{*}$ & $22.99 \pm 1.9^{*}$ \\
\hline
\end{tabular}

Values are represented as mean $\pm \mathrm{SE}\left({ }^{*} \mathrm{P} \leq 0.05\right.$ compared to control group $\mathrm{G} 1, \# \mathrm{P} \leq$ 0.05 compared to the G3). G1: control rats, G2: control rats injected with PVPE, G3: alkali esophageal burn; G4: alkali esophageal burn with PVPE treatment. Data obtained from groups of ten rats each $(n=10)$. 
Table 5: IFN- $\gamma$ levels (st.u.) in esophageal tissue homogenates obtained from the rats

\begin{tabular}{ccccc}
\hline IFN- $\gamma$ (st.u.) & 7 days & 14 days & 21 days & 31 days \\
\hline G1 & $31.63 \pm 1.2$ & $31.14 \pm 2.1$ & $33.75 \pm 1.3$ & $33.04 \pm 1.7$ \\
G2 & $32.42 \pm 1.4$ & $31.52 \pm 2.2$ & $33.96 \pm 2.6$ & $33.76 \pm 1.3$ \\
G3 & $38.63 \pm 3.7^{\star}$ & $36.47 \pm 2.3^{\star}$ & $35.75 \pm 2.4$ & $35.04 \pm 1.4$ \\
G4 & $38.45 \pm 2.5^{\star}$ & $35.29 \pm 2.7$ & $35.44 \pm 2.8$ & $34.99 \pm 1.4$ \\
\hline
\end{tabular}

Values are represented as mean $\pm \mathrm{SE}\left({ }^{\star} \mathrm{P} \leq 0.05\right.$ compared to control group G1, \#P $\leq 0.05$ compared to the G3). G1: control rats, G2: control rats injected with PVPE, G3: alkali esophageal burn; G4: alkali esophageal burn with PVPE treatment. Data obtained from groups of ten rats each $(n=10)$.

Table 6: IL-4 levels (st.u.) in esophageal tissue homogenates obtained from the rats

\begin{tabular}{ccccc}
\hline IL-4 (st.u.) & 7 days & 14 days & 21 days & 31 days \\
\hline G1 & $38.01 \pm 2.5$ & $36.47 \pm 2.4$ & $38.2 \pm 1.5$ & $35.83 \pm 1.4$ \\
G2 & $35.95 \pm 2.4$ & $35.68 \pm 2.6$ & $39.2 \pm 1.5$ & $36.8 \pm 1.4$ \\
G3 & $29.52 \pm 1.9^{*}$ & $30.26 \pm 1.9^{*}$ & $36.31 \pm 1.4$ & $33.76 \pm 1.3$ \\
G4 & $32.74 \pm 1.8^{*}$ & $32.41 \pm 1.4^{*}$ & $36.52 \pm 1.4$ & $35.4 \pm 1.4$ \\
\hline
\end{tabular}

Values are represented as mean $\pm \mathrm{SE}\left({ }^{*} \mathrm{P} \leq 0.05\right.$ compared to control group $\mathrm{G} 1, \# \mathrm{P} \leq 0.05$ compared to the G3). G1: control rats, G2: control rats injected with PVPE, G3: alkali esophageal burn; G4: alkali esophageal burn with PVPE treatment. Data obtained from groups of ten rats each $(n=10)$.

Table 7: IL-10 levels (st.u.) in esophageal tissue homogenates obtained from the rats

\begin{tabular}{ccccc}
\hline IL-10 (st.u.) & 7 days & 14 days & 21 days & 31 days \\
\hline G1 & $47 \pm 2.9$ & $46.53 \pm 1.8$ & $45.85 \pm 1.8$ & $44.48 \pm 1.7$ \\
G2 & $48.11 \pm 2.8$ & $46.85 \pm 0.6$ & $45.63 \pm 1.8$ & $44.69 \pm 1.7$ \\
G3 & $32.25 \pm 2.4^{*}$ & $28.13 \pm 1.2^{*}$ & $36.87 \pm 1.4^{*}$ & $45.92 \pm 1.8$ \\
G4 & $35.71 \pm 2.7^{*}$ & $38.4 \pm 1.5^{*}$ & $38.13 \pm 1.5^{*}$ & $46.2 \pm 1.8$ \\
\hline
\end{tabular}

We investigated changes in levels of proinflammatory cytokines (such as IL- $1 \beta$, IL-12 $\beta$, IFN- $\gamma$, IL-6, TNF- $\alpha$ ) which can enhance the proliferation of $\mathrm{T}$ - and B- lymphocytes, antibody synthesis, production of adhesion molecules, and synthesis of acute phase proteins. Also, they are involved in processes of specific and non-specific immunity. IL- $1 \beta$ is one of the key cytokines in wound defense and regulation. The data obtained for IL- $1 \beta$ levels in esophageal homogenate supernatants show that IL- $1 \beta$ increases in the condition of AEB 2 during all period of the experiment (Table 1). Our data are consistent with the literature, which also show increases in IL- $1 \beta$ concentration in tissues and plasma with inflammatory wounds ${ }^{18}$ compared to intact animals (Table 1). IL-6 acting as a pleiotropic cytokine that is involved in the growth and differentiation of numerous cell types. In our study, we showed that there was an increase of IL-6 in conditions of alkali burn esophagus (Table 2). IL- $12 \beta$ is crucial for immune response amplification as well as the initiation of protective mechanisms against infections. Monocytes, macrophages, neutrophils, lymphocytes are basic producers of IL-12 $\beta$, microbial components are the main inductors of IL- $12 \beta$ synthesis. The basic target cells for IL- $12 \beta$ are natural killers and T lymphocytes. IL- $12 \beta$ activates T-lymphocyte differentiation and cytotoxic activity ${ }^{10}$. Pro-inflammatory cytokines IFN- $\gamma$ and TNF- $\alpha$ play an immunomodulatory function and they are considered as inducers of cellular immunity, which are functionally related to other crucial pro-inflammatory cytokines. We showed an increase of levels of IFN- $\gamma$ (Table 5) and IL-12 $\beta$ (Table 3) in esophageal homogenate supernatants in rats with the AEB 2 during all time of the investigation. We admit an increase in the level of TNF- $\alpha$ on day 7 th and then the level of TNF- $\alpha$ decreased on day 14 th 
and for the rest of the experiment (Table 4). It was established that one of the factors promoting the IL-6 increase in the inflammation area may be the increase of IL-4 (negative correlation) ${ }^{10}$. Changes in the content of Anti-inflammatory cytokine IL-4 can be regarded as a prognostic factor for post wounded complications ${ }^{19}$. Anti-inflammatory cytokines are able to inhibit pro-inflammatory cytokine activity, suppress T-lymphocyte proliferation, and participate in immune responses to various antigens. In our study, we showed that there was an increase in levels of IL-4 (Table 6) and IL-10 (Table 7) in rat's esophageal homogenate supernatants after alkali burn of esophagus 2 degree.

Plants, including herbs, contain polyphenols, which are a potential source of natural antioxidants. Herbal extracts and their products prevent or reduce oxidative stress. The reported in literature anti-inflammatory mechanisms included reduction of some pro-inflammatory cytokines, and increasing anti-inflammatory IL-10 secretion, reduction of cyclooxygenase-2 (COX-2) and nitric oxide synthase expression $^{20}$. In our experiment, we showed some normalization of inflammatory indicators due to the introduction of the extract, which may be a sign of the positive effect of the extract on the healing of alkaline burn of the esophagus.

\section{CONCLUSIONS}

Our results revealed imbalance of pro-inflammatory and anti-inflammatory cytokines in esophageal homogenates in rats with alkali burn of esophagus second degree, which can indicate a prolonged inflammation in the burned area. In the groups of animals with the alkaline burn of the esophagus, that were injected extract there can be traced a change of the indicators in the direction of normalization, indicating about the obvious therapeutic effect of aqueous extract of pods of Phaseolus vulgaris.

\section{ABBREVIATIONS}

AEB 2: Alkali esophageal burn of second degree ANOVA: Analysis of variance

COX-2: Cyclooxygenase-2

ELISA: The enzyme-linked immunosorbent assay

PVPE: Phaseolus vulgaris pods extract

\section{COMPETING INTERESTS}

None of the authors of this article have conflicting interests.

\section{AUTHORS' CONTRIBUTIONS}

Ya. B. Raetska - the experiment planning, article planning and writing; V.V Dmytryk - measurement of the indicators presented in the article; N.M. Chornenka measurement of the indicators presented in the article; O.M Savchuk - the experiment planning, article planning and writing; T. I Halenova - the experiment planning, extract of pods of Phaseolus vulgaris preparation; N. G. Raksha -measurement of the indicators presented in the article; T. Vovk- the experiment planning, extract of pods of Phaseolus vulgaris preparation; L.I. Ostapchenko - the experiment planning. All authors reviewed and commented on final draft.

\section{REFERENCES}

1. Raetska YB, Ischuk TV, Dzhus OI, Savchuk OM, Ostapchenko LI. Experimental modeling of 1st and 2nd degrees alkali esophageal burn in immature rats. Bio Systems. 2014;6(1):3944.

2. Koval TV, Ishchuk TV, Grebinyk DM, Ya BR, Sokur OV, Savchuk $\mathrm{OM}$, et al. Matrix metalloproteinase functioning in case of esophagus acid burn. Biomedical Research. 2018;29(16).

3. Tan JQ, Zhang HH, Lei ZJ, Ren P, Deng C, Li XY, et al. The roles of autophagy and apoptosis in burn wound progression in rats. Burns. 2013;39(8):1551-6. PMID: 23751274. Available from: 10.1016/j.burns.2013.04.018.

4. Koltuksuz U, Mutuş HM, Kutlu R, Ozyurt H, Cetin S, Karaman A, et al. Effects of caffeic acid phenethyl ester and epidermal growth factor on the development of caustic esophageal stricture in rats. Journal of Pediatric Surgery. 2001;36(10):1504-9. PMID: 11584397. Available from: 10. 1053/jpsu.2001.27032.

5. Singer AJ, McClain SA, Taira BR, Guerriero JL, Zong W. Apoptosis and necrosis in the ischemic zone adjacent to third degree burns. Academic Emergency Medicine. 2008;15(6):54954. PMID: 18616442. Available from: 10.1111/j.1553-2712. 2008.00115.x.

6. Singer AJ, Clark RA. Cutaneous wound healing. N Engl J Med. 1999;(341):738-46.

7. Tiwari VK. Burn wound: how it differs from other wounds? Indian J Plast Surg. 2012;(45):364-73. Available from: 10.4103/ 0970-0358.101319.

8. Sommer K, Sander AL, Albig M, Weber R, Henrich D, Frank $J$, et al. Delayed wound repair in sepsis is associated with reduced local pro-inflammatory cytokine expression. PLoS One. 2013;8(9):e73992. PMID: 24086305. Available from: 10.1371/journal.pone.0073992.

9. Xue $\mathrm{M}$, Jackson $\mathrm{CJ}$. Extracellular matrix reorganization during wound healing and its impact on abnormal scarring. Advances in Wound Care (New Rochelle, NY). 2015;4(3):119-36. PMID: 25785236. Available from: 10.1089/wound.2013.0485.

10. Raetska Y, Chornenka N, Koval T, Savchuk O, Beregova T, Ostapchenko L. Cytokine profile indicators in rat blood serum in a model of esophagus burn induced by antioxidant chemical preparation. Biomed Res Ther. 2017;4(9):1591-1606. Available from: 10.15419/bmrat.v4i9.367.

11. Kondo T, Ohshima T. The dynamics of inflammatory cytokines in the healing process of mouse skin wound: a preliminary study for possible wound age determination. International Journal of Legal Medicine. 1996;108(5):231-6. PMID: 8721421. Available from: 10.1007/BF01369816.

12. Kyznetsova MY, Makieieva OM, Lavrovska DO, Tymoshenko MO, Sheverova DP, Halenova TI, et al. Effect of aqueous extract from Phaseolus vulgaris pods on lipid peroxidation and antioxidant enzymes activity in the liver and kidney of diabetic rats. Journal of Applied Pharmaceutical Science. 2015;5:1-6. Available from: 10.7324/JAPS.2015.50501. 
13. Halenova TI, Vareniuk IM, Roslova NM, Dzerzhynsky ME, Savchuk OM, Ostapchenko LI, et al. Hepatoprotective effect of orally applied water-soluble pristine C60 fullerene against $\mathrm{CCl} 4$-induced acute liver injury in rats. RSC Advances. 2016;6(102):100046-55. Available from: 10.1039/ C6RA20291H.

14. Pejnović N, Lilić D, Zunić G, Colić M, Kataranovski M, Dujić A. Aberrant levels of cytokines within the healing wound after burn injury. Archives of Surgery (Chicago, III). 1995;130(9):999-1006. PMID: 7661688. Available from: 10. 1001/archsurg.1995.01430090085025.

15. Finnerty CC, Jeschke MG, Herndon DN, Gamelli R, Gibran N, Klein $\mathrm{M}$, et al. Temporal cytokine profiles in severely burned patients: a comparison of adults and children. Molecular Medicine (Cambridge, Mass). 2008;14(9-10):553-60. PMID: 18548133. Available from: 10.2119/2007-00132.Finnerty.

16. de Bandt JP, Chollet-Martin S, Hernvann A, Lioret N, du Roure LD, Lim SK, et al. Cytokine response to burn injury: relationship with protein metabolism. The Journal of Trauma.
1994;36(5):624-8. PMID: 8189461. Available from: 10.1097/ 00005373-199405000-00004.

17. Liu Q, Xiao S, Xia Y. TWEAK/Fn 14 Activation Participates in Skin Inflammation; 2017. Available from: 10.1155/2017/6746870.

18. Finnerty CC, Herndon DN, Przkora R, Pereira CT, Oliveira HM, Queiroz DM, et al. Cytokine expression profile over time in severely burned pediatric patients. Shock (Augusta, Ga). 2006;26(1):13-9. PMID: 16783192. Available from: 10.1097/ 01.shk.0000223120.26394.7d.

19. Kim HS, Kim JH, Yim H, Kim D. Changes in the levels of interleukins 6, 8, and 10, tumor necrosis factor alpha, and granulocyte-colony stimulating factor in Korean burn patients: relation to burn size and postburn time. Annals of Laboratory Medicine. 2012;32(5):339-44. PMID: 22950069. Available from: 10.3343/alm.2012.32.5.339.

20. Mueller M, Hobiger S, Jungbauer A. Anti-inflammatory activity from extracts from fruits, herbs and spices. Food Chemistry. 2010;122(4):987-96. Available from: 10.1016/j.foodchem. 2010.03.041. 